\title{
The Significance of the Issue of Events' Identity under Different Descriptions for Social Theory and Social Philosophy
}

\author{
Pavel M. Stepantsov
}

\begin{abstract}
The paper concerns the problem of event's identity under different descriptions. The point is that the whole dictionary of action-language would be inconsistent and ambiguous if we cannot prove that some of different descriptions are about identical events. One simply would not be in position to speak intelligibly on the topics of an action, agency, intention, and responsibility and so on. In this paper I consider the questions as follows. Is there actually only one thing happening when the event occurs, e. g. someone performs a bodily movement, say, pushing the switch to turn the light on? Or we can speak about principally different actions of a person? Can a person by making a bodily movement perform different action in the same time? Do intentional actions differ in their nature from unintentional events?
\end{abstract}

Index Terms-Action, description, event, identity, intentionality, Wittgenstein.

\section{INTRODUCTION}

This text is intended to expose the significance of the problem of event's identity for social philosophy and to link it with the issues of intentionality and in particular with intended and unintended consequences of actions.

To start with, a useful intuition that our actions have intended and unintended consequences are provided, for instance, by Giddens:

Consider the so-called 'accordion effect' of action. An

individual flicks a switch to illuminate a room. Although this is intentional, the fact that the turning on of the switch alerts a prowler is not. Supposing the prowler flees down the road, is caught by a policeman, and after due process spends a year in gaol on the basis of being convicted of the burglary. Are all these unintended consequences of the act of flicking the switch? Which are things the individual has 'done'? [1].

It follows that by acknowledging the presence of unintended consequences of action we face up with distinguishing the things merely brought about by the action from what the agent has actually done. Put in other way, it is the question of agency which is closely related to the issues of intentionality. Through the making a single 'bodily movement', that is, flipping the switch, agent turned the light on (what is his intentional action), informed the prowler of his coming back (it was a thing he had done unintentionally but nevertheless it can still be considered as

Manuscript received March 11, 2013, revised May 10, 2013.

Pavel M. Stepantsov is with the University of Russian Presidential Academy for National Economy and Public Administration, Russian Federation (e-mail: pavel.stepantsov@gmail.com). what (s)he has done) and brought about his imprisonmenttoo many actions for a single bodily movement. Are all of them different actions or just distinct descriptions tracing divergent aspects and consequences of the event? And, finally, where are the 'boundaries' distinguishing a single event of action from another single event?

\section{BODY PART}

Davidson has originally introduced the example with my flipping the switch [2]. His point is that one does not have to perform two distinct actions-flipping the switch and, thereafter, illuminating the room. It is senseless to suppose that these descriptions have different referents. In other words, he argues that it would be misleading to treat a single occurrence as summoning up different actions. One would not be in a position to account for action and explain it, if (s) he considered that a single doing may bring about different actions. Rather an action should be identified with event and the event gives rise for the only action being redescribed and explained in different ways.

The idea becomes clearer if we recall Davidson's example with the Queen's killing the King.Let us suppose we have two observers of the same event and consider they are producing different accounts of what they have observed (I will call these accounts descriptions in what follows). Suppose that these accounts are contradictive in some significant points. I will take an example from Davidson's essay 'Agency' (1971). Suppose a following situation: Queen poured the poison into the King's ear what caused his death later. Davidson states, we can give a plenty of descriptions for the event. These are some of them:

For some examples: 'The queen moved her hand thus causing the death of the king' $<\ldots>$ or, 'The queen killed the king' $<\ldots>$; or, 'The queen emptied the vial into the king's ear' $<\ldots .>$. Many of these expressions are equivalent: for example, 'The queen killed the king by pouring poison in his ear' and, 'The queen poured poison in the king's ear thus causing his death'. And obviously the longer descriptions entail many of the shorter ones [2].

Then we can imagine two possible descriptions of this situation, say these ones:

- The queen poured the poison into the king's ear

- The queen killed the king

Note that it seems that both these descriptions are the correct descriptions of the same event. But is it really so? Suppose somehow counterfactually to the Shakespeare's 'Hamlet' there was a trial to establish whether the queen had actually killed the king. Two witnesses gave the 
accounts of what had happened and let us suppose their accounts were accurately these descriptions. The question is whether in such case it is so obvious for us, that these descriptions do refer to the same event? It seems to me that the answer should be 'no'. Our doubts may be caused by two factors. First of all, the evidences of witnesses can really be descriptions of different events. The rationale behind this is, as Davidson notes, that "we should observe that we may easily know that an event is a pouring of poison without knowing it is a killing, just as we may know that an event is the death of Scott with knowing it is the death of the author of Waverley" (Ibid, p. 149). Secondly, we can notice that in fact the witnesses do themselves pretend that they are describing different events. The first witness claims (contrary to the second) that the Queen just poured the poison into the King's ear (without killing him) and his death was caused by another factor (no matter which one). The second one says that there is not a case that the Queen poured the poison into the King's air without killing him, in fact it was killing (so the events are not such and such as the first one claims). Do these witnesses pretend that both their descriptions are the descriptions of the same event? Rather they suppose that they specify different counterfactual events. So far the question whether we can determine, if these descriptions refer to the identical event or not, cannot be answered through the analysis of these descriptions themselves. We can imagine situations in which the pouring was the killing as well as it was not. Hence it can be a case that 1) and 2) are referring to different events and at the same time it is possible that they really are descriptions of the identical event.

This statement looks a little bit trivial. But the insight Davidson provides us with is as follows. In our hypothetical case $^{1}$ the trial would be impossible if the descriptions of the different witnesses referred to different events ${ }^{2}$. In fact a judge has to make a decision about the case that is the specific event causing the King's death. (S) he is not dealing with different cases under different descriptions but with the single event described in different ways. So far (s) he needs to choose among these descriptions the correct one since they seem to be contradictive ${ }^{3}$. So far the judge considers that these different descriptions correspond to the same event.

The point behind this reasoning is as follows. It is ridiculous to suppose that after poisoning the King the Queen would have to perform another action, say, killing him for true. It is ridiculous as well to claim that for illuminating the room I needed to do something else my flipping the switch. So far Davidson concludes that by providing more extensive description of the action one does not describe it by appealing to other events.

It is evident that the relation between the queens's moving her hand in such a way as to pour poison in the king's ear, and her killing him, cannot be the relation of

\footnotetext{
${ }^{1}$ We assumed that a trial occurred to establish whether the Queen actually killed the King

${ }^{2}$ Suppose an example of such distinct events: witnesses could in fact refer to different Queens.

${ }^{3}$ Notice that they actually contradict one another because they give incompatible descriptions of the single event. They would not be contradictive at all if the first one witnessed, say, about the English Queen and the Second one described the doings of the Dutch Queen.
}

event causality. If it was, we would have to say the queen caused herself to kill the king $\langle\ldots\rangle$ then we could ask how she did this causing. The only answer I can imagine is that she did it by moving her hand in that way. But this movement was by itself enough to cause the death of the king - there was no point to a further action on the part of the queen [3].

In fact we just re-describe this action. Moreover, it would be impossible to describe action in terms of its reasons at all if the description were related to different events, e. g. flipping the switch was not the same as the turning the light on.

Davidson says that there are a lot of things we can do only because we are able to give different descriptions referring to the same event. For instance we could not apologize otherwise:

It is hard to imagine a satisfactory theory of action if we cannot talk literally of the same action under different descriptions. Jones managed to apologize by saying 'I apologize'; but only because, under the circumstances, saying 'I apologize' was apologizing. Cedric intentionally burned the scrap of paper; this serves to excuse his burning a valuable document only because he did not know the scrap was the document and because his burning the scrap was (identical with) his burning the document [2].

And more precisely about excuses:

'I didn't know it was loaded' belongs to one standard pattern of excuse. I do not deny that I pointed the gun and pulled the trigger, nor that I shot the victim. My ignorance explains how it happened that I pointed the gun and pulled the trigger intentionally, but did not shoot the victim intentionally. That the bullet pierced the victim was a consequence of my pointing the gun and pulling the trigger. It is clear that these are two different events, since one began slightly after the other. But what is the relation between my pointing the gun and pulling the trigger, and my shooting the victim? The natural and, I think, correct answer is that the relation is that of identity. The logic of this sort of excuse includes, it seems, at least this much structure: I am accused of doing $\mathrm{b}$, which is deplorable. I admit I did a, which is excusable. My excuse for doing $b$ rests upon my claim that I did not know that $\mathrm{a}=\mathrm{b}[2,94]$.

So far Davidson argues that in the case with excuses both my shooting the victim (description a) and my pointing the gun and pulling the trigger (description $b$ ) do not refer to different events, but are about one identical event which I red scribe in different manners. And this makes my claim that I did not know that $\mathrm{a}=\mathrm{b}$ (i. e. that my pulling the trigger was identical (event) with my killing the victim) intelligible.

The point behind these examples taken from Davidson's works is that a great deal of social deeds is possible only because one can describe the same event in different ways. So far the main question I will attempt to answer in what follows concerns the feasibility of giving different accounts of what have been done. This claim leads us to further conclusions about the nature of intention and agency.

What does it mean to say that my action was intentional? Consider our example with illuminating the room. We can say that I flipped the switch, turned the light on and by the 
way unbeknownst to me I also alert a prowler to the fact that I am home. If we believe that these descriptions refer to different actions we can say that some of the actions being described are intentional while others are not. Perhaps, the last one was not intentional. And what is about the first and the second ones? Have I performed them intentionally? Well, we may be tempted to think that I flipped the switch intentionally since my reason was my desire for turning the light on. So I have simultaneously performed two different actions and there were two distinct events, such that the last one (my turning the light on) makes the first one (flipping the switch) intentional. And my turning the light on was intentional on the behalf of its own. But why this is so? What is so specific to be found in the second action that makes the first one intentional? What should we look for within this occurrence to answer the question? We can find a probable answer formulated Giddens: "This concept [intentionality] I define as characterizing an act which its perpetrator knows, or believes, will have a particular quality or outcome and where such knowledge is utilized by the author of the act to achieve this quality or outcome" $[4,10]$. So far intentionality becomes a kind of extra feature, and, we can add, another event, different from the action itself which is additional but necessary for any action to be intentional one. However, it is misleading as any search for such additional 'element of intentionality'. Anscombe provides us with instructive demonstration of why there is no reason to look for any feature, attendant to the action, which makes it intentional:

That an action is not called 'intentional' in virtue of any extra feature which exist when it is performed, is clear from the following: Let us suppose that there is such feature, and let us call it 'I'. Now the intentional character of the action cannot be asserted without giving the description under which it is intentional, since the same action can be intentional under one description and unintentional under another. It is however something actually done that is intentional if there is an intentional action at all. A man no doubt contracts certain muscles in picking up a hammer; but it would generally be false to call his contraction of muscles the intentional act that he performed. This does not mean that his contraction of muscles was unintentional. Let us call it 'preintentional'. Are we to say that $I$, which is supposed to be the feature in virtue of which what he does is an intentional action, is something which accompanies a preintentional action, or movement of his body? If so, then the pre-intentional movement and I guarantee that an intentional action is performed [4, 28].

Anscombe argues further, that if it is actually the case, then 'I' should accompany any intentional action and to have an effect on agent's actual behavior, that is contracting muscles, flipping the switch e.t.c. So far ' $\mathrm{I}$ ' becomes a distinct event or more precisely a distinct intentional action itself. Then we need 'another $I$ ' to add to 'I' to make it intentional. And so on. Anscombe concludes that this reflection demonstrates that assumption of the existence of some entity, which accompanies an action and makes it intentional, leads us to confusions. There is no any actual occurrence enabling us to call an action intentional. There are different descriptions of an event instead which accounts for it as being intentional or not:

And in describing intentional actions as such, it will be a mistake to look for the fundamental description of what occurs - such as the movements of muscles or molecules - and then think of intention as something, perhaps very complicated, which qualifies this. The only events to consider are intentional actions themselves, and to call an action intentional is to say it is intentional under some description that we give (or could give) of it [4, 29].

Anscombe's point is following: there is nothing peculiar in events, we call intentional actions, to be discovered to find out, what intention is. Our capacity to account for some events as intentional actions rests upon the possibility to provide different descriptions of the same event. And under some descriptions, we can give, this action is intentional. Davidson acknowledges Anscombe's input into the discussion of the issue of intentionality [3]. He picks up her claim that we can consider an action to be intentional if and only if we can account for it as intentional under some of its descriptions: "if an event is an action, then under some description(s) it is primitive, and under some description(s) it is intentional" $[3,58]$. Davidson argues that by describing an action as being intentional, one rationalizes it, that is, gives the desires and beliefs of an agent who have performed the action ${ }^{4}$.

Well, was my 'informing' the prowler about the fact that I am at home by means of flipping a switch an intentional action? The answer is 'no'. One may describe my action in such a way; however, it will not make the action different from my intentional illuminating the room, sincemy informing the prowler that I have come back is identical with my intentional action of illuminating the room. It is a single event described in different ways. Therefore, the germ of the argument is that some descriptions may specify an action as being intentional one, while other ones concentrate upon its unintended consequences. Nevertheless, it is an identical event of action all these possible descriptions will refer to. Otherwise, we were inclined to say that by means of my single doing (flipping the switch) I have performed an enormous amount of actions, and some of them are intentional and others are not. We have already seen that this position leads to confusions making us to assume that there is another thing one has to perform to illuminate the room, except pushing the switch.

And what should be said about the chain of unintended consequences of the action? What events am I agent of? My action can call forth infinite happenings; does it mean that all of them are the things I have done? Where does my responsibility for what has happened come to the end? Where does my action 'finish'?

Consider for example Brutus's stabbing of Caesar. Is he responsible for killing Caesar? Was he an agent of Caesar death? How far do the scopes of his agency extrapolate?

${ }^{4}$ It could be a problem for Davidson to explain how the reasons for action can cause it and at the same time may serve to rationalize an action through its re-description. This problem lies out of the scopes of the present discussion; we use Davidson's works to direct our attention towards the problems of sociological speaking about events and actions. Discussions of this problem see at Mele [6]. 
Was he an agent of the only event or of all those ones he had brought about? For example, is Brutus responsible for Augustus becoming an emperor? To some extend he is. But was he an agent of this event? And should we describe his action of stabbing Caesar as making Augustus an emperor? It is unclear where we should break off the chain of events, which Brutus's action of stabbing Caesar made happen, to say what the action was. Normally, we are inclined to say that Brutus action was stabbing Caesar as well as killing him but do not describe it as the action of making Augustus an emperor. But why?

Davidson states that only in the case we assume that it is possible for (some of) different descriptions to refer to the same action we will have a coherent way of talking about actions. However, we do not refer to any further effects the action has brought about

To say someone did something intentionally is to describe the action in a way that bears a special relation to the beliefs and attitudes of the agent; and perhaps further to describe the action as having been caused by those beliefs and attitudes. But of course to describe the action of the agent as having been caused in a certain way does not mean that the agent is described as performing any further action [2, 104].

If it were impossible for different descriptions ${ }^{5}$ to correspond with an identical event, and by giving different descriptions we always talked about different events then we would be unclear how to distinguish one action from another. In such a case one could say that an agent makes a plenty of divergent actions by a single doing (what is misleading), and one would be unclear how to differentiate different actions.

Sharrock and Hughes have finely outlined this point:

Consider the following description of fairly mundane acts: 'He raised his arm', 'He raised the glass', He toasted the happy couple', 'He assuaged his thirst', 'He decided that the only thing to do was get drunk'. All these statements describe what could be said to be different actions and yet could also be said to consist of, or involve, much the same bodily movement [5].

Though these descriptions can refer to divergent actions, it is a necessary condition for our action-talk that they in some situations may be considered being statements about the same actions:

Some of these descriptions might well impute a motive or purpose to the behavior such as a desire to get drunk, be sociable, wish luck to the happy couple, and assuage a thirst and so on. In such cases what the motive does is tell us more about the action that is being performed $<\ldots>$ in describing many actions we are unavoidably involved in imputing motives of one sort or another. [5].

So far our ability to account for our actions in different fashion is itself 'essential to there being a social life at all'. By means of different descriptions we learn more about the action. Any new description gives us additional knowledge about the event described. Two conditions should be satisfied for our ability to talk informatively about actions: different descriptions must (1) give us different bits of information about the event and (2) refer to the same event.
These conditions are necessary for the action-talk all of us are involved in to be meaningful.

\section{CONCLUSION}

I have intended to demonstrate above that the whole dictionary of action-language would be inconsistent and ambiguous if we cannot prove that some of different descriptions are about identical events. One simply would not be in position to speak intelligibly on the topics of an action, agency, intention, and responsibility and so on.

The way out from the difficulty is to recognize that there is actually only one thing happening when the event occurs, e. g. someone performs a bodily movement, say, pushing the switch to turn the light on. It is misleading to suppose that by a bodily movement one does a number of actions, and some of them are intentional (like turning the light on), others are not (for instance altering the prowler to the fact I am at home). To get out of this difficulty one should recognize the possibility of different descriptions referring to the same and single event.

\section{REFERENCES}

[1] A. Giddens, The Constitution of Society, Outline of the Theory of Structuration, Cambridge UK: Polity Press, 1984

[2] D. Davidson, "Actions, Reasons and Causes," IEEE Journal of Philosophy, vol. 60, no. 23, Nov. 1963, pp. 685-700.

[3] D. Davidson, "Agency," IEEE Essays on Actions and Events, 2nd Edition, Oxford, UK: Clarendon Press, 2001, pp. 305-312.

[4] G. E. M. Anscombe, Intention, Cambridge, Massachusetts, England: Harvard University Press, 2000.

[5] J. Hughes and W. Sharrock, The Philosophy of Social Research, 3rd Edition, London UK: Longman Press, 1997.

[6] A. R. Mele, "Philosophy of Action," IEEE Donald Davidson, ed. by K. Ludwig, Cambridge, UK: Cambridge University Press, 2003, pp. 137-162.

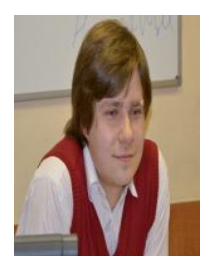

P. M. Stepantsov was born on January $10^{\text {th }} 1988$ in Moscow. He is MA in Sociology (University of Manchester) and currently is on PhD program at the State University Higher School of Economics (Moscow). Pavel is a lecturer at the Faculty of Sociology and Philosophy and a senior research fellow at Centre for Sociological Research at the Russian Presidential Academy of National Economy and Public Administration. His research interests lies on the intersection on sociological the orisons faction, epistemology and philosophy of language. 